\title{
Produção textual em livros didáticos de terceiro ano de ensino médio: concepções de
} linguagem e ensino

\author{
Rita de Cássia Antonia Nespoli Ramos ${ }^{1}$
}

\begin{abstract}
Resumo
A experiência com o ensino de língua portuguesa e a convivência com livros didáticos ensejaram o questionamento sobre quais são as concepções de linguagem e de ensino que avalizam esses materiais didáticos. Escolheu-se como material de análise o livro de Terceiro Ano de Ensino Médio de Maria Emília Amaral et al. Nas discussões, busca-se respaldo no referencial investigativo e metodológico descrito nos estudos dialógicos desenvolvidos, principalmente, por Bakhtin e Volochínov. Como resultados, depreende-se que o material apresenta duas concepções de linguagem e de ensino, uma centrada em uma visão de que o ensino-aprendizado deve seguir um trajeto e outra pautada na interação e no diálogo.
\end{abstract}

Palavras-chave: Concepções de Linguagem; Ensino; Língua Portuguesa.

Textual production in third year educational books middle school: conceptions of language and teaching

\section{Abstract}

The didactic teaching of Portuguese language and a didactic teaching class and questioning about which are like conceptions of language and teaching that endorse the didactic materials. The book of the Third Year of High School of Maria Emília Amaral et al. was chosen as an analysis material. In the discussions, we seek to respond, not referential, investigative and methodological, in dialogical studies, mainly Bakhtin and Volochínov. As it behaves in a way that presents both conceptions of language and teaching, a teaching-learning approach must follow a path; and the other pattern of interaction and no dialogue.

Keywords: Language Concepts; Teaching; Portuguese Language.

\section{Introdução}

De 1986 a 1996, em nossa experiência no magistério público, o ensino de Português nas escolas de periferia de Campinas tinha um instrumento imprescindível: os mimeógrafos. Como o orçamento era precário, os textos "rodados" em folhas de sulfite, geralmente doadas para a professora pelos alunos, não permaneciam com os estudantes, mas circulavam em várias salas de aula e eram motivo de leitura e de pretexto para a Gramática e a Produção Textual. Nas aulas de leitura, eram utilizadas as caixas, cheias de livros literários e paradidáticos, um chamativo para a leitura como fruição ou para a elaboração de debates, resenhas, resumos. Já o livro didático era uma das fontes para as práticas pedagógicas; neles se procuravam textos, exercícios,

\footnotetext{
${ }^{1}$ Universidade Metodista de Piracicaba, Piracicaba, ritanespoli@uol.com.br.
} 
explicações e conceitos, os quais, por sua vez, eram acrescidos pelo docente com os próprios conhecimentos teórico-linguísticos a partir do conhecimento que tinha da classe.

De 2004 a 2015, com o reingresso na rede pública, esta pesquisadora passou a utilizar o Material de Apoio da Secretaria da Educação do Estado de São Paulo, os Cadernos do Professor e do Aluno, destinado aos professores da rede, tendo a oportunidade de escolher os Livros Didáticos por meio do Programa Nacional do Livro Didático.

Concomitante ao magistério na rede pública, há vinte e cinco anos, trabalhou na rede particular, principalmente no terceiro ano do Ensino Médio (EM), no qual as aulas de "Redação" ganham importância, embora sejam fortemente direcionadas ao vestibular. Nesse sentido, este artigo procura refletir sobre a concepção de linguagem e de ensino em que se sustentam os livros didáticos aprovados no Programa Nacional de Livros Didáticos de Língua Portuguesa do Ensino Médio.

Escolheu-se, então, a "Coleção Novas Palavras", de Emília Amaral et al. (2016), mais especificamente os enunciados presentes no volume do terceiro ano do Ensino Médio, na seção "Leitura e Produção Textual". A preferência deu-se em razão de essa obra ter sido selecionada pelos professores no Programa Nacional do Livro Didático em 2018, 2016 e 2014. Assim, as propostas de atividades para a produção textual serão ponto de partida para se estudar a concepção de linguagem e de ensino.

Para a discussão, busca-se respaldo no referencial investigativo e metodológico descrito nos estudos enunciativo-discursivos desenvolvidos, principalmente, por Bakhtin/Volochínov e procura-se estabelecer as relações (inter)discursivas presentes nos enunciados dos materiais de análise. Para relacionar esse aporte teórico às questões de ensino, mais especificamente de português, buscou-se trabalhar com autores que concebem a língua portuguesa a partir dos estudos da linguagem.

O arcabouço teórico e investigativo possibilita que a análise dos livros didáticos ultrapasse a percepção das instruções objetivas ali apresentadas, pois será possível inserir os enunciados em discursos sobre o ensino. Com essa descrição, poder-se-ão determinar as concepções de linguagem e de ensino que subjazem aos materiais e se eles marcam a importância de o professor ser responsável e valorizado no processo de ensino-aprendizado. Nessa perspectiva, o livro didático seria o que se propõe: mais um material de que o professor 
poderia apropriar-se para elaborar suas aulas. Além disso, a análise permitirá difundir práticas que ajudem a vencer um discurso muito propagado nas escolas de que se o livro didático for "eficiente", o docente poderá segui-lo, mesmo não tendo tempo para preparar aula ou sem uma formação adequada. Entende-se, então, que o livro didático pode se tornar o protagonista no ensino e essa percepção desvaloriza o professor.

Para avançar nessas discussões, organizou-se o artigo em quatro seções. Na primeira, tem-se a intenção de apresentar uma breve trajetória do Programa Nacional do Livro Didático (PNLD) e do Guia do PNLD, imbricados com certas leis que conferem a viabilidade a esse material. A seguir, a ideia é contextualizar os livros didáticos e as polêmicas que envolvem esses instrumentos de ensino. Na segunda, a proposta consiste em apresentar o arcabouço teóricoinvestigativo bakhtiniano e dos autores que estudam as concepções de linguagem relacionadas ao ensino de língua portuguesa. A terceira apresenta a descrição do material escolhido para a análise e, na quarta seção, apresentam-se as discussões dos dados. Essa trajetória, em nosso ver, permitirá que se depreendam os discursos constituintes em que emergem os enunciados do Livro Didático escolhido para a discussão.

\section{O PNLD e os Livros Didáticos}

Batista (2003), ao fazer um estudo sobre a trajetória do Programa Nacional do Livro Didático, afirma que "é uma iniciativa do Ministério da Educação (MEC). Seus objetivos básicos são a aquisição e distribuição, universal e gratuita, de livros didáticos para alunos de escola pública" (BATISTA, 2003, p.25). Essa iniciativa, para o estudioso, direciona as relações do Estado com os livros didáticos e faz com que o MEC seja um intermediário entre a produção industrial e os professores.

Para Batista (2003), um conjunto de leis e documentos "embasam as propostas de mudança dos livros didáticos" (BATISTA, 2003, p.42). Isto porque, em sua visão, a Lei das Diretrizes e Bases (LDB), em 1996, procurou valorizar as experiências cotidianas do aluno, inclusive as vividas fora da escola, o que lhe confere um caráter de enfrentamento dos índices de retenção. As Diretrizes Curriculares Nacionais para o Ensino Fundamental, em 1998, criam condições para a elaboração e aplicação da proposta pedagógica da escola, destacando o 
trabalho coletivo. E os Parâmetros Curriculares Nacionais (PCN) para o Ensino Fundamental propõem critérios que devem embasar a elaboração do livro didático (BATISTA, 2003). Essa conjuntura propicia uma política nacional de distribuição e avaliação de livros didáticos.

Cabe destacar que, desde 1937, há políticas públicas para distribuição de livros didáticos, mas, apoiada em leis e documentos, uma importante mudança operou-se no PNLD em 1996, quando, de acordo com Batista (2003), o Ministério da Educação (MEC), além de adquirir e distribuir os livros às escolas, passou a preocupar-se com a qualidade e correção da obra. O PNLD passa a atender quase todo o país (com exceção de São Paulo e Minais, regiões que se incluem no programa em 2002) e estende-se a todas as disciplinas obrigatórias. Além disso, instaura-se a avaliação pedagógica dos livros escolhidos pelos professores e distribuídos às instituições de ensino.

Batista (2003) destaca que, concomitante a essa decisão, muitos estudos contestavam a qualidade do material, pois, além de ser o único material do professor, as pesquisas questionavam, principalmente, o "caráter ideológico e discriminatório, sua desatualização, suas incorreções conceituais e suas influências metodológicas" (BATISTA, 2003, p.28).

Nesse período, o Ministério da Educação (MEC) firmou critérios de avalição dos livros didáticos, dentre os quais se destacam: a) os critérios comuns de análise, que buscavam observar a "adequação didática e pedagógica, a qualidade editorial e gráfica, a pertinência do manual do professor para uma correta utilização do livro didático e para a utilização do docente" (BATISTA, 2003, p.30); b) os critérios eliminatórios, que se referem às questões de discriminação e a erros conceituais.

Batista (2003) aponta que, em 1996, apresentaram-se os resultados dessa avaliação dos livros de Português, Matemática, Ciências e Estudo Sociais de 1a a 4a séries e "a análise gerou uma classificação dos livros em quatro grandes categorias" (BATISTA, 2003, p.30-31): excluídos, não-recomendados, recomendados com ressalvas, recomendados.

Em 1996, segundo o autor, os resultados dos processos de avaliação foram apresentados para diferentes setores:

No campo da produção do livro, a divulgação se fez por meio do encaminhamento às editoras de um laudo técnico de cada um de seus livros excluídos e não-recomendados pelo PNLD, composto por uma ficha de avaliação e por um parecer elaborado pelas comissões de avaliação (BATISTA, 
2003, p.31).

No campo do consumo, por sua vez, a divulgação foi feita de duas maneiras: debate na imprensa e, pela primeira vez no PNLD, a publicação de um Guia de Livros Didáticos, no qual todos os livros que reuniram qualidades suficientes para serem recomendados (com ou sem ressalvas) foram apresentados aos professores. (BATISTA, 2003, p.32, grifos do autor). A intenção do guia era favorecer a escolha do livro pelos professores. Conforme o estudioso, o PNLD/1999, no que the diz respeito, excluiu a categoria "não-recomendados" e adotou um novo critério de exclusão: a incorreção e a incoerência metodológica (BATISTA, 2003).

Se, conforme o autor, ao longo de 1960 e 1970, havia um manual didático que estruturava o trabalho docente, não é de se estranhar que, em 1980, houvesse uma forte rejeição ao livro didático, pois o material era entendido como uma tecnologia pouco adequada às práticas de sala de aula e estruturado "apenas aos efeitos de controle que exerce sobre a ação docente e sobre o currículo" (BATISTA, 2003, p.45). No entanto, para o estudioso, o interesse da pesquisa acadêmica, o surgimento de grupos que investigam esses materiais e a reorganização de práticas pedagógicas possibilitam que os livros didáticos sejam vistos de forma diferente.

O autor não desconsidera o fato de o livro poder ser apenas um paliativo para perpetuar as condições de trabalho do professor e pontua a capacidade de o Programa servir para a manutenção dos Manuais Didáticos de outras décadas, os quais consideravam que o professor tinha uma formação inadequada e faltava tempo para que ele preparasse atividades didáticas. Para Batista (2003), é preciso que o PNLD contribua para novas concepções do livro didático e, para tanto, é preciso que "[...] dê acolhida à proposta de novos modos de relação do manual com o trabalho docente; possibilite uma renovação dos padrões editoriais associados ao conceito de livro didático que se cristalizou na tradição brasileira" (BATISTA, 2003, p.49). Essas questões encaminham o autor a postular que a escolha de livro pelo professor deve contemplar a sua formação e o seu fortalecimento.

Alencar (2017), em sua tese de doutorado, discorre que o PNLD começou a distribuir livros para o EM a partir de 2004 e já iniciou a avalição das obras selecionadas. Em 2005, todas as regiões do Brasil passaram a ser atendidas pelo Programa e, em 2008, houve a distribuição para todas as disciplinas. Em 2015, uma nova informação é publicada nos documentos: “a oportunização de entrega de livro digital" (ALENCAR, 2017, p.114), o que possibilitou, em nosso 
ver, uma maior divulgação dos conteúdos.

A autora também procura entender os documentos oficiais, como os PCN e o PNLD inseridos nas políticas públicas e direcionados ao Ensino Médio. Assim, de acordo com a pesquisadora, em 2009, quando o Ensino Médio se tornou obrigatório e universal, houve documentos oficiais que procuravam orientar como elaborar os materiais didáticos. Alencar (2017) destaca a Lei de Diretrizes e Bases da Educação Nacional (LDBEN) (BRASIL, 1996) que estabelece objetivos para o Ensino Médio; as Diretrizes Curriculares para o Ensino Médio (DCNEM/2013), nas quais há a contextualização do EM; os Parâmetros Curriculares do Ensino Médio (PCNEM) (BRASIL, 2000) e Orientações Curriculares para o Ensino Médio (OCEM) (BRASIL, 2006), responsáveis pela elaboração do currículo; e os Parâmetros Curriculares Nacionais Mais (PCN+) (BRASIL, 2002), em que há os parâmetros e as orientações curriculares para o Ensino Médio.

Nesses documentos, principalmente nos PCN, as concepções de linguagem alcançaram maior difusão. Vários documentos foram elaborados para orientar as práticas docentes em relação à linguagem, dentre os quais se destacam os Parâmetros Curriculares Nacionais para o Ensino Médio. Abaixo, reproduzimos um trecho que sustenta essa afirmação, retirado do PCNEM:

Não há linguagem no vazio, seu grande objetivo é a interação, a comunicação com um outro, dentro de um espaço social, como, por exemplo, a língua, produto humano e social que organiza e ordena de forma articulada os dados das experiências comuns aos membros de determinada comunidade linguística (BRASIL, 2000, p.5).

As Orientações Curriculares também disseminam determinada concepção de linguagem:

o aprendizado da língua implica a apreensão de práticas de linguagem, modos de usos da língua construídos e somente compreendidos nas interações, o que explica a estreita relação entre os participantes de uma dada interação, os objetivos comunicativos que co-constroem e as escolhas lingüísticas a que procedem. Em outras palavras, a assunção desse ponto de vista determina que o trabalho com a língua(gem) na escola invista na reflexão sobre os vários conjuntos de normas - gramaticais e sociopragmáticas - sem os quais é impossível atuar, de forma bem-sucedida, nas práticas sociais de uso da língua de nossa sociedade (BRASIL, 2006, p.30). 
Para Wittke (2007), os Parâmetros Curriculares Nacionais são elaborados por especialistas e propõem o desenvolvimento de competências, mas não mais o acúmulo de informações. Para ela, esse esforço envolve "tanto a elaboração de currículos plurais, próprios de cada região, como a construção de materiais didáticos que possibilitem a prática desses conhecimentos". (WITTKE, 2007, p.22). A autora discorre que, para o EM:

[...] os Parâmetros estão organizados em três áreas: Linguagem, Códigos e suas Tecnologias; Ciência da Natureza, Matemática e suas Tecnologias; Ciências Humanas e suas Tecnologias, construindo uma concepção curricular transdisciplinar, direcionada à construção integral do aluno, enquanto ser humano (WITTKE, 2007, p.23).

Wittke (2007) destaca que os Parâmetros Curriculares Nacionais apresentam uma concepção de linguagem que é fundamentada na orientação desenvolvida por Bakhtin. "Sob essa consideração, a linguagem/língua corresponde a uma visão de mundo plena de significações, que vai além de seu aspecto formal" (WITTKE, 2007, p.25), os conteúdos remetem assim às questões enunciativas e às variações linguísticas. A autora indaga se os professores estão preparados para conviver com essa perspectiva linguística e se os livros didáticos são elaborados a partir dessa ótica.

Conforme indicamos, com os documentos oficiais e a distribuição de livros didáticos, certas teorias de linguagem e de ensino circularam, com mais ênfase, no ambiente escolar. Isso porque os Livros Didáticos são oferecidos às escolas que se inscrevem no processo de distribuição do Programa Nacional de Livros Didáticos (PNLD) e têm acesso a dois documentos: a "Apresentação ao Guia Nacional do Livro Didático" e o "O Guia Nacional do Livro Didático".

No primeiro material, logo na introdução, em comunicado dirigido a professores e professoras, os autores pontuam que haverá informações que contribuirão para as escolhas do professor. Em carta dirigida aos docentes, o documento coloca-se como um meio de auxiliar os professores a escolher os livros que serão adotados e conhecer "os princípios didáticos e pedagógicos que moveram a avaliação pedagógica das obras inscritas" (BRASIL, 2017a, p.6). Além disso, apresenta-se uma novidade; os livros são avaliados "por professores da Educação Básica com larga experiência no magistério" (BRASIL, 2017a, p.6). As disciplinas contempladas 
no Guia são: Arte, Biologia, Filosofia, Física, Geografia, História, Língua Estrangeira Moderna Espanhol, Língua Estrangeira Moderna Inglês, Língua Portuguesa, Matemática, Química e Sociologia. E há um Guia de Livros Didáticos específico para cada componente curricular.

Um ponto a se considerar é que, no material “Apresentação do PNLD”, discorre-se sobre as questões metodológicas e as estratégias de ensino, assim expresso:

\begin{abstract}
Auxiliar no desenvolvimento das aulas sem retrair a autonomia docente: um bom livro didático não se furta de oferecer ao(à) professor(a) um planejamento detalhado e coerente para as aulas, assumindo o seu papel de atuar como um manual. Todavia, não pode desempenhar tal função prescindindo do professor e secundarizando a sua atuação. Professores(as) devem desempenhar um papel ativo, crítico e criativo em relação às propostas subjacentes ao livro didático[...] (BRASIL, 2017a, p.12).
\end{abstract}

Além de ressaltar a importância do professor como protagonista do ensino, o material também apresenta considerações sobre o aluno, pois o livro, na visão do material, deve ser sensível aos interesses, às linguagens e às lutas sociais dos jovens.

No Guia do PNLD/2018 de Língua Portuguesa, por sua vez, reafirmam-se os papéis dos professores e dos alunos:

[...] você e seus estudantes são os grandes protagonistas de uma prática de ensino bem-sucedida. Um docente, de posse de um bom material, pode formar centenas de estudantes preparados para os desafios políticos, econômicos e sociais com os quais se deparam as pessoas no exercício da cidadania na contemporaneidade [...] (BRASIL, 2017b, p.7).

Apesar de, nos dois documentos, alertar-se para a importância do professor como sujeito autônomo, Silva (1996) defende, enfaticamente, que "o livro didático se apresenta como uma insubstituível muleta" (SILVA, 1996, p.11). Para o autor, com uma formação precária e condições de ensino ingratas, "resta a esses professores engolir e reproduzir a idéia de que sem a adoção do livro didático não há como orientar a aprendizagem" (SILVA, 1996, p.11). Segundo o estudioso, essa "aceitação" está inserida em uma tradição sustentada em um olhar saudosista, nas propagandas feitas pelas editoras e na própria imagem que o professor tem dele mesmo e da educação. Escolher ou não o livro didático, na visão do autor, independe do docente. 
Lajolo (1996) postula que os livros didáticos determinam conteúdos e condicionam estratégias de ensino, "marcando, pois, de forma decisiva, o que se ensina e como se ensina o que se ensina" (LAJOLO, 1996, p.4). Para a autora, a interação entre livro didático e professor é positiva quando o autor do material apresenta "os pressupostos teóricos que assume e segue relativamente tanto à matéria de que trata o livro quanto a questões de educação e aprendizagem." (LAJOLO, 1996, p.5)

Para Silva (1996),

[...] só a reinserção do professor na condição de sujeito insubstituível do ato de ensinar poderá varrer a barbárie pedagógica das escolas, higienizando os ambientes e pondo para fora dali os badulaques que, por força das circunstâncias e dos costumes, insistem em permanecer na categoria dos didáticos (p.13).

Temos, então, instaurada uma polêmica, pois, dada a importância e a grande circulação que o Livro Didático ganhou nos últimos anos, parece que a escola não pode prescindir desse instrumento nas aulas, com sua apresentação didática, comportamentos destinados a professores e alunos, aulas programadas e um planejamento em etapas. Por outro lado, apesar de pautar, no modo de dizer, que o professor e o aluno são protagonistas do ensino, os "passos" e as etapas propostos nas atividades podem servir como um engessamento às práticas dos professores e retirar sua autonomia. Para refletir sobre essas questões, a proposta é partir dos enunciados do material escolhido e depreender os discursos que dele emergem. Nessa perspectiva, propomos abordar, a seguir, os estudos dos discursos e as pesquisas sobre concepções de linguagem e ensino.

\section{Concepções de linguagem, de língua e de ensino}

Quanto às concepções de linguagem e língua, o Guia PNLD/2018 apresenta necessidade da leitura e da escrita de diversos gêneros e afirma que: "é necessário privilegiar abordagens discursivo-enunciativas da língua, indo além do nível da frase". (BRASIL, 2017b, p.10). No que diz respeito à Produção Textual, o Guia do PNLD/2018 defende que os materiais didáticos devem ter: 
[...] atenção aos diferentes letramentos; aos contextos de produção da escrita; aos processos de planejamento, escrita e reescrita, em função da situação comunicativa e dos objetivos do texto; às diferentes linguagens envolvidas na produção de textos multimodais; às orientações quanto aos usos das modalidades mais ou menos formais da língua relacionadas às situações comunicativas; entre outros (BRASIL, 2017b, p.13).

Esses enunciados entendem a linguagem como "interação" e sustentam-se nos estudos sobre a linguagem. Para entendê-los a respeito das questões discursivas e enunciativas, neste artigo, o suporte teórico são os estudos dialógicos propostos por Bakhtin e Volochínov (2006) e Bakhtin (2003). Ao se associar os discursos sobre a linguagem com as concepções de ensino, propõem-se algumas ponderações com base nos estudos de Travaglia (2001), em “Gramática e Interação: uma proposta para o ensino de gramática no 1ㅇ e 2 Graus"; e em duas obras de Geraldi: "Portos de Passagem" (1997) e o "Texto na sala de aula" (2006).

Bakthin e Volochínov (2006), a princípio, em seus estudos sobre a linguagem, discorrem sobre duas orientações para a atividade da linguagem: o subjetivismo idealista e o objetivismo abstrato. Para a primeira, a criação é individual e o centro da produção de linguagem; a língua, por sua vez, é percebida como um produto pronto, fixo e imutável. A segunda pressupõe que o centro da criação da linguagem consiste em um sistema linguístico, externo ao falante, e se relaciona às "formas fonéticas, gramaticais e lexicais da língua" (BAKHTIN; VOLOCHÍNOV, 2006, p.79).

O autor contesta essas orientações, pois, em sua visão, "enunciação monológica fechada constitui, de fato, uma abstração" (BAKHTIN; VOLOCHÍNOV, 2006, p.1007). Em outras palavras, não se pode conceber um falante que enuncie a partir de sua própria fonte ou que haja um sistema abstrato que possa explicar os fatos da linguagem. Para o autor russo, a enunciação deve ser entendida como "interação", pois a "situação social mais imediata e o meio social mais amplo determinam completamente e, por assim dizer, a partir do seu próprio interior, a estrutura da enunciação" (BAKHTIN; VOLOCHÍNOV, 2006, p.117).

Na concepção apresentada, a língua vai além de uma estrutura que se organiza em um sistema de formas e implica em um "diálogo", no qual a palavra do outro já está presente no enunciador e, assim, antecipam-se críticas, objeções, por exemplo. A essas antecipações, o autor 
chama de "réplica": "compreender é opor à palavra equivalente uma contrapalavra". (BAKHTIN; VOLOCHÍNOV, 2006, p.137). Além disso, a língua é entendida como em constante mudança e transformação. Nessa concepção, cada enunciado é apreendido como uma resposta aos enunciados precedentes. Essa resposta, desse modo, entra em diálogo com os enunciados, pois: "[...] ela os rejeita, confirma, completa, baseia-se neles, subentende-os como conhecidos, de certo modo os leva em conta. Porque o enunciado ocupa uma posição definida em uma dada esfera da comunicação, em uma dada questão, em um dado assunto etc." (BAKHTIN, 2003, p.297).

Não se pode, então, centrar a linguagem em função do sujeito ou do objeto, mas devese entender que, ao se enunciar as palavras, forma elos, cadeias dentro de enunciados, gerando atitudes responsivas.

Associando os estudos da linguagem e os estudos sobre o ensino de língua materna, Travaglia (2001) propõe a linguagem como expressão do pensamento e como instrumento de comunicação. Para a primeira, a enunciação não é afetada pela situação de produção ou pelo outro e privilegia-se o raciocínio lógico e a construção de frases corretas tendo como parâmetros as gramáticas tradicionais em um viés normativo. A segunda, por seu turno, percebe a língua como um "código" em que há emissores e receptores que transmitem uma mensagem. O código é um sistema de normas gramaticais externo ao falante e exclui as situações de produção.

Para a terceira concepção, por fim, de acordo com Travaglia (2001), a linguagem é:

entendida como uma forma ou processo de interação. Nessa concepção o que o indivíduo faz não é tão somente traduzir e exteriorizar um pensamento, ou transmitir informações a outrem, mas sim realizar ações, agir, atuar sobre o interlocutor (ouvinte/leitor). A linguagem, é pois um lugar de interação humana, de interação comunicativa pela produção de efeitos de sentido entre interlocutores, em uma dada situação de comunicação e em um contexto sóciohistórico e ideológico (TRAVAGLIA, 2001, p.23).

Nos estudos de linguagem e sua relação com o ensino, Geraldi $(2006$, p.41) postula que a concepção de linguagem como instrumento de comunicação está ligada à teoria da comunicação e entende a língua como um código - conjunto de signos que se combinam segundo regras capaz de transmitir ao receptor certa mensagem. Ainda nas palavras do autor: "Em livros didáticos, é a concepção confessada nas instruções ao professor, nas introduções, nos títulos, 
embora em geral seja abandonada nos exercícios gramaticais" (GERALDI, 2006, p.41). A linguagem como forma de interação verbal, por sua vez, pressupõe ir além da transmissão de informações e a linguagem é vista como lugar de interação humana.

Quanto à produção textual, Geraldi (1997, p.136) estabelece a distinção entre Produção de textos e Redação. Nesta, segundo o autor, "produzem-se textos para a escola; naquela produzem-se textos na escola". Na Produção Textual, é preciso se considerar que as condições de produção exigem que: a) se tenha o que dizer; b) se tenha uma razão para dizer o que se tem a dizer; c) se tenha para quem dizer o que se tem a dizer; d) o locutor se constitua como tal, enquanto sujeito que diz o que diz para quem diz (ou, na imagem wittgensteiniana, seja um jogador no jogo); e) se escolham as estratégias para realizar (a) (b) (c) (d).

Cabe lembrar ainda que esse modo de conceber a linguagem e o ensino-aprendizado evita alguns mitos em relação à língua. Corrobora-se essa afirmação com os estudos de Possenti (1996) sobre a impossibilidade de acreditar em uma língua uniforme, mas na urgência de entender a língua como "variação". Isto porque, de acordo com o autor, as variedades são funcionais e fontes de recursos alternativos, assim, quanto mais numerosos forem estes, mais expressiva pode ser a linguagem humana (POSSENTI, 1996).

A esses estudos de língua como um fenômeno vivo que se transforma e que não pode ser entendido como único, juntam-se os trabalhos de Bagno (2002), nos quais o autor postula que não é lícito entender a língua como "um pacote fechado, um embrulho pronto e acabado", mas que ela "é viva, dinâmica, está em constante movimento - toda língua viva é uma língua em decomposição e em recomposição, em permanente transformação" (BAGNO, 2002, p.117).

Partindo desses pressupostos teóricos, entende-se que se pautar em uma concepção de língua como "interação" pressupõe um ensino que não se vincula unicamente às questões gramaticais, mas que considera a situação de produção. Além disso, filiados a essa perspectiva que procura observar os efeitos de sentido que se pode depreender do texto, tem-se uma visão de ensino em que professor e aluno dialogam a partir da unidade textual.

Por fim, na perspectiva abordada, não se pensa em conteúdos com a finalidade em si mesmos, mas observam-se os elementos linguísticos que funcionam como marcas textuais que ajudam na construção textual. Assim, entende-se que a escrita não é descontextualização, mas os interlocutores escrevem em determinado contexto social de escrita de acordo com o objetivo 
a eles proposto. A partir dos gêneros discursivos, os alunos serão instigados a refletir sobre os argumentos, a linguagem, o público alvo, os recursos gramaticais empregados em texto para, assim, poderem organizar suas próprias produções.

Ao se trabalhar com esses pressupostos, é preciso pensar que a reescrita deve ser uma atividade constante nas produções textuais, pois, nessa ação, o discente é motivado a repensar sua produção e tem uma oportunidade para refazer seu texto. É necessário pensar sobre as concepções de linguagem como interação na produção de textos em livros didáticos.

\section{Descrição do material de análise e procedimentos metodológicos}

A “Coleção Novas Palavras" organiza-se em Livro do Estudante e Manual do Professor. Cada volume estrutura-se em três partes: Literatura, Gramática e Leitura e Produção de Textos. O Manual do professor, por sua vez, é o mesmo do aluno, mas com respostas e orientações em vermelho e ainda há uma seção intitulada "Conversa com o professor", com a concepção teóricometodológica que se propõe a ser material de apoio ao professor.

A parte intitulada "Leitura e Produção Textual" é dividida em cinco capítulos:

Quadro 1: Síntese das propostas de leitura e produção textual

\begin{tabular}{|c|c|c|}
\hline Capítulo & Tema dos capítulos & $\begin{array}{c}\text { Seções recorrentes em todos os } \\
\text { capítulos }\end{array}$ \\
\hline 1 & Dissertação Argumentativa & - Amplie seus conhecimentos \\
\hline 2 & $\begin{array}{l}\text { Dissertar e descrever: a delimitação do } \\
\text { tema }\end{array}$ & - Em tom de conversa \\
\hline 3 & $\begin{array}{l}\text { Dissertar e narrar: assumindo um } \\
\text { ponto de vista }\end{array}$ & - Leitura e Produção \\
\hline 4 & $\begin{array}{l}\text { Argumentação causal. A importância } \\
\text { dos exemplos. Carta }\end{array}$ & $\begin{array}{l}\text { - Critérios de avaliação e } \\
\text { reelaboração }\end{array}$ \\
\hline 5 & Estratégias lógico-expositivas & $\begin{array}{l}\text { - Resumindo o que você estudou } \\
\text { - Atividades }\end{array}$ \\
\hline
\end{tabular}

Fonte: Proposta de produção textual, Novas Palavras, vol.3.

Periódico Horizontes - USF - Itatiba, SP - Brasil - e020031 
Em cada capítulo, a abordagem do conteúdo é organizada em etapas e privilegia o gênero "Dissertação": Essas etapas são: a) distinção entre a "Dissertação Argumentativa" e a "Dissertação Expositiva", as partes da dissertação: introdução, desenvolvimento e conclusão, b) os elementos da dissertação: assunto, tema, tese e defesa de um ponto de vista, c) estratégias de argumentação, d) como a narrativa e descrição contribuem para a dissertação.

Há boxes com as "palavras dos especialistas", nos quais há conceitos de estudiosos das teorias sobre o texto ou reproduzem-se as palavras do Ministério da Educação, publicadas em documentos sobre a Redação do ENEM (o que é dissertação e como elaborá-la).

Nas atividades para "Leitura e produção", há exercícios e propostas como: a) identificar os elementos da dissertação; b) promover a divisão do texto nas três partes da dissertação, a partir de textos pertencentes a diferentes gêneros, como artigos de opinião, quadrinhos; c) elaboração de respostas dissertativas a partir de artigos de opinião, quadrinhos, propostas de vestibulares; d) propostas de produção com extensão mais curta ou mais longa; e) propostas de elaboração de outros gêneros: currículo, entrevista, por exemplo.

Nessa seção, também se apresentam os critérios de avaliação e reelaboração: adequação ao tema; ampliar vocabular, como fator de coesão e coerência; progressão textual, clareza; concisão e expressividade.

Com observação da trajetória proposta pelo material, é possível estabelecer relações entre os enunciados do Livro Didático e a história da produção de teorias linguísticas e com o imaginário do que ensinar. Assim, como metodologia, procedeu-se à leitura dos enunciados relativos à "Leitura e Produção Textual", e a seguir, foram recortados os trechos em que se apresentam propostas de produção. Fez-se, então, uma separação dos enunciados aos quais, por uma questão metodológica, denominamos de "produções curtas" e "produções longas". As primeiras referem-se ao pedido de produção de repostas, a partir dos textos propostos pela obra, ou à elaboração de introduções, conclusões e comentários. A segunda relaciona-se a Propostas de Produção mais longas, nas quais se estabelecem condições para uma Redação completa (introdução, desenvolvimento e conclusão). A discussão dos dados recairá sobre estas últimas. Escolheram-se três atividades de escrita: duas, retiradas de vestibulares, e outra, proposta elaborada pelos autores do material. 
A seguir, buscou-se relacionar os conceitos apresentados para a escrita a teorias linguísticas, as quais, por sua vez, foram associadas à concepção de linguagem, como "código", como "instrumento" ou como "interação". A partir dessa associação é que se pode entrever as construções das imagens do professor, do aluno e configurar a concepção de ensino.

Para refletir sobre os enunciados, acredita-se que os estudos bakhtinianos propõem formalmente uma teoria e/ou uma análise dos discursos, mas, segundo Brait (2008), permitem sustentar as análises linguísticas e literárias, levando em consideração a historicidade, os sujeitos e o social.

Cabe destacar que as explanações de Brait (2008) sobre as contribuições de Bakhtin para a teoria e para a análise dialógica do discurso orientam que esse arcabouço não configura uma proposta "fechada" e "organizada", mas apresenta e descreve conceitos, noções e categorias que "especificam a postura dialógica diante do corpus discursivo, da metodologia e do pesquisador" (BRAIT, 2008, p.29).

Em nosso ver, a perspectiva discursiva avaliza este artigo. Isto porque, do ponto de vista teórico-metodológico, as análises partirão do conceito de dialogismo proposto pelo filósofo russo para entender os discursos que se imbricam e nos quais emergem os enunciados.

Nessa visão de análise, não se considera que os enunciados nascem da vontade do sujeito, mas procura-se entender a relação que ele estabelece com a História, sem que tenha conhecimento desse fato. Assim, parte-se dos elementos linguísticos para refletir sobre os discursos que fazem emergir os enunciados que o sujeito apresenta, os quais não são transparentes, mas atravessados pela História.

\section{Discussão dos dados e resultados}

A seguir, apresentamos as propostas de produção de textos do denominado "produções longas" que serão foco dessa discussão: 
Quadro 2: Proposição para produção textual

\section{(I) ENEM/MEC PROPOSTA DE REDAÇÃO}

A partir da leitura dos textos motivadores seguintes e com base nos conhecimentos ao longo de sua formação, redija texto dissertativo-argumentativo em modalidade escrita formal da língua portuguesa sobre o tema: "A persistência da violência contra a mulher na sociedade brasileira", apresentando proposta de intervenção que respeite os direitos humanos. Selecione, organize e relacione, de forma coerente e coesa, argumentos e fatos para a defesa de um ponto de vista (AMARAL et al, 2016, p.349, grifos dos autores).

Fonte: Proposição para a produção textual, Novas Palavras, vol.3.

Ao retomar a concepção discursiva, verifica-se na proposta um vocabulário dos estudos linguísticos, como os termos "dissertação", "coerente", "coesa". Assim, os elementos da escrita não são organizados apenas a partir das regras gramaticais, mas também das estruturas textuais. Com essa determinação, os interlocutores e as estratégias para compor o texto ficam por conta das coerções de gênero, enfatizada a especificação do caráter da dissertação a ser produzida: argumentativa.

Encontra-se, ainda, no trecho transcrito, as expectativas projetadas do saber do aluno, colocado no papel de candidato ao vestibular. Espera-se dele, na escrita, que reconheça aspectos relacionados aos "argumentos", ao tipo de dissertação, à coesão e à coerência. Supõe-se que essas determinações sobre como escrever sejam desenvolvidas, principalmente, no ambiente escolar. Além disso, há determinação de aspectos que vão além da escrita formal e da organização do texto, como respeitar os direitos humanos, debater sobre a violência contra a mulher, o que sinaliza uma proposta que extrapola as questões de estrutura e de gramática e respondem, nas relações discursivas, aos critérios de escolha do Livro Didático: respeitar os direitos humanos e de minorias.

Apesar de certos elementos que apontam para a contextualização, como essa proposta de escrita é trabalhada no ambiente escolar, deve-se considerar que se trata de uma "Redação" que prepara o aluno para o "depois", o ingresso no vestibular, e a expectativa pode ser de um interlocutor, o professor, que agirá apenas como corretor, sem diálogos sobre o texto. Além disso, não há previsão de circulação do texto (qual é o objetivo, quem 
seria o interlocutor).

Ao apresentar a diferença entre os tipos de dissertação (expositiva e argumentativa), o material o faz a partir de uma fala do Ministério da Educação sobre a redação do ENEM. Abaixo transcrevemos o trecho publicado no box "o que dizem os especialistas":

[...] a compreensão da proposta de redação - esta exige [...] um texto dissertativo-argumentativo, que é o tipo de texto que demonstra a verdade de uma ideia ou tese. É mais do que uma simples exposição de ideias. Nessa redação, o participante deve evitar elaborar um texto de caráter apenas expositivo. É preciso apresentar um texto que expõe um aspecto relacionado ao tema, defendendo uma posição, uma tese [...]. O tema constitui o núcleo das ideias sobre as quais a tese se organiza. Em âmbito mais abrangente, o assunto recebe uma delimitação por meio do tema, ou seja, um assunto pode ser abordado por diferentes temas. (BRASIL. Ministério da Educação. Exame Nacional do Ensino Médio (ENEM). A redação do ENEM 2013: guia do participante. Brasília. DF: Diretrizes de Avaliação da Educação Básica (Daeb)/ Instituto Nacional de Estudos e Pesquisas Educacionais Anísio Teixeira (INEP, p.13) (AMARAL et al, 2016, p.295).

Ao selecionar a fala de "especialistas" a partir de documentos sobre a redação, o autor do material avaliza um jeito de pensar a "dissertação" sustentado nas propostas de avaliação do vestibular, o que pode excluir a reescrita, por exemplo, pois, nessa situação de escrita, o texto é visto como um "produto pronto", no qual não cabe a intervenção do professor.

O livro apresenta atividades de produção textual, geralmente retiradas do vestibular, o que pode construir uma imagem, em sala de aula, de que a finalidade do ensino da escrita é o processo seletivo. Principalmente ao se considerar a importância que o Volume 3 credita à "dissertação", gênero escolhido por vestibulares como a UNESP, USP e ENEM. A seguir, apresentamos mais uma proposta dessa categoria:

Quadro 3: Proposição para produção textual

(I) Leia a proposta de dissertação da Fuvest e faça o que se pede, utilizando os textos de modo direto ou indireto.

(Fuvest-SP). Redija uma dissertação em prosa, relacionando os três textos a seguir. (AMARAL et al, 2016, p.322, grifos dos autores)

Fonte: Proposição para produção textual, Novas Palavras, vol.3. 
Nessa proposta, a produção textual fica restrita à composição textual "dissertação", não mais "argumentativa", mas "em prosa". A ausência de restrições pode associar ao texto apenas as questões gramaticais e tornar a esvaziar o sentido de produzir textos. Enfatizam-se os aspectos composicionais e estilísticos previstos para o gênero do discurso a ser produzido - a dissertação em prosa - e coloca-se em primeiro plano o tipo de texto.

Há de se pontuar que essas propostas de produção são apresentadas a alunos de terceiro ano do Ensino Médio, no ambiente escolar, e as imagens construídas do ensino de língua portuguesa estão presentes: o aluno deve saber a modalidade escrita e saber o que é uma "dissertação". Assim, ao se apresentarem propostas de redação de vestibulares, apesar de essa concepção entrar em contradição com a concepção de "produção textual", esse comportamento antecipa críticas de, por exemplo, ser um material descontextualizado com o ingresso no ensino superior. Além disso, reforça a imagem de que o aluno do terceiro ano deve "treinar" para a Redação do vestibular.

Além das propostas retiradas do vestibular, há uma, no que se refere à produção da dissertação, elaborada pelos autores do material. Após a apresentação de quadrinhos sobre um robô sensível e o contraste com a insensibilidade do homem, há algumas questões com respostas pessoais dos alunos e apresenta-se a seguinte proposta para a dissertação:

Quadro 4: Proposição para produção textual

Escolha uma das propostas e crie sua dissertação. Não se esqueça do título e de se posicionar claramente em relação aos motivos pelos quais você pensa e de expor como acha que se deveria agir, em cada caso. Não se esqueça também de que o texto deve ser dissertativo-argumentativo.

\section{Proposta 1}

A. Pense duas vezes antes de agir

B. Aja duas vezes antes de pensar

\section{Proposta 2}

A. Na hora de escolher a profissão, é preciso seguir uma vocação, para que se tenha felicidade profissional.

B. Na hora de escolher a profissão, é preciso seguir o mercado, para que se tenha sucesso profissional. (AMARAL et al, 2016, p.321-322)

Fonte: Proposição para produção textual, Novas Palavras, vol.3.

Observa-se a reprodução de um jeito de elaborar propostas presentes nos vestibulares: não se apresenta a cena enunciativa, em que haveria os interlocutores, não se explicita um propósito 
para a escrita: onde os textos circularão, se haverá reescrita. Ressoa a dissertação, nos moldes do vestibular, "dissertativo-argumentativo", e a avaliação mais restrita a questões formais do gênero.

A descrição das etapas para o ensino-aprendizagem da dissertação consiste em sustentar os conceitos, em alguns momentos, em documentos sobre a "Redação do ENEM", apresentar diversos exercícios do vestibular, publicar propostas com pouca contextualização. O Livro Didático analisado avaliza uma concepção de ensino pautada em práticas artificiais que conduzem e amarram o professor em uma visão de ensino com pouca autonomia.

Concomitante a essa visão mais tradicional de ensino, em que a escrita restringe-se à estrutura composicional, o que pode privilegiar as questões gramaticais de "clareza", "correção"; há no material uma perspectiva de "interação" da escrita (já sugerida por escolher Redações do Enem, as quais, de certa forma, apresentam alguns elementos de contextualização). Isso ocorre, por exemplo, na apresentação de outros gêneros como a carta, o debate regrado, propostas de vestibulares que abordam gêneros de modo contextualizado. Nessas propostas de produção, os autores do material descrevem várias condições para a escrita, que, em nosso ver, dão sentido a essa prática. Abaixo, reproduz-se uma dessas atividades: 
Nesta proposta será necessário empregar descrição técnica e a capacidade de relacionar texto e elementos contextuais, além de habilidade para convencer e persuadir o interlocutor, utilizando tanto a linguagem escrita quanto a oral.

a) Fase de apresentação escrita

\section{Trabalho individual}

Pense na profissão que gostaria de ter e, em função dela e do universo em que se insere, elabore um currículo, com o objetivo de ser aceito como estagiário e qualificar-se para exercê-la.

\section{Trabalho em grupo}

Reúna-se com alguns colegas e discutam os currículos elaborados, trocando sugestões e aperfeiçoandoos. Em seguida, definam o(s) currículo(s) mais interessante(s), a fim de reuni-lo(s) aos definidos pelos outros grupos e pendurá-los no mural da classe.

Observação: Para realizar esta fase da atividade, faça pesquisa na internet sobre tipos de currículo, considerando que esse tipo de documento é um gênero textual que apresenta informações pessoais do candidato para instituições, empresas e outros locais onde se pretende trabalhar. Portanto a seleção de informação (objetivos da candidatura, qualificações e experiência, por exemplo) deve ser objetiva e adequada ao tipo de atividade profissional escolhido, e a linguagem empregada deve estar de acordo com a norma-padrão.

b) Fase da apresentação oral

1. Cada grupo deve escolher o currículo de um outro grupo e simular uma entrevista para seu autor, que pode utilizar as sugestões de seu grupo para responder às questões propostas.

2. Após as entrevistas, você e seus colegas discutem a atividade e avaliam o desempenho de todos no desafio de escrever um currículo, formular questões e respondê-las em uma entrevista de caráter profissional. (AMARAL et al, 2016, p.306, grifos dos autores)

Fonte: Proposição para a produção textual, Novas Palavras, vol.3.

Há a preocupação de apresentar diversas atividades para a pré-escrita: elaboração de um currículo; o trabalho sobre o texto: discussão sobre os currículos produzidos; a pesquisa sobre a estrutura e os elementos desse gênero; as indicações para a produção: informações objetivas, adequação ao cargo profissional. Além desses elementos, a proposta de apresentação oral implica em estimular o aluno a entender a escrita não como antítese da fala, mas em perspectiva de que há textos escritos e orais que devem ser elaborados em linguagem formal. Por fim, a proposta de elaborar uma entrevista e a avaliação dos próprios alunos aponta para visões da escrita como um processo que envolve a reescrita e diversos leitores.

Associados a essa construção de escrita mais contextualizada, há os critérios para reescrita apresentados no material, que contemplam tanto as questões gramaticais quanto a argumentação e coerência textual.

Essa perspectiva abre espaço para debates e para a interação entre alunos-alunos e alunos-professores e pode favorecer a autonomia desses agentes no ensino-aprendizagem.

Em nosso ver, o gênero "dissertação" ainda parece ser visto como um gênero cujas 
condições de produção podem ser subentendidas, pois a estrutura composicional parece, no imaginário, falar por si só; enquanto outros gêneros, como os apresentados no material: debate regrado, entrevistas, exigem que se considere uma cena enunciativa mais ampla, na qual se contextualiza a escrita. Nossa prática escolar avaliza esse entendimento, pois as condições para a escrita da dissertação quase se restringem à abordagem do tema.

A partir das concepções de língua, linguagem e escrita, é possível depreender que há uma heterogeneidade constitutiva no material, visto que se apresentam duas concepções de escrita: como produção e como redação. As duas parecem ser bem aceitas na sociedade, pois nelas ressoam práticas escolares e do vestibular.

Com a descrição dessas concepções, pode-se, ainda, observar os papéis creditados aos professores e aos alunos, no que se refere ao ensino da escrita. De um lado, os professores devem se inserir em uma visão mais tradicional de educação, na qual conduzirão os alunos a assimilarem uma estrutura composicional sustentada em grandes vestibulares e pouco serão protagonistas no ensino. Por outro, a abertura para o debate a partir de gêneros discursivos diversos, a proposta com a intertextualidade (vídeos, sites) podem contribuir para o protagonismo do professor, com a perspectiva de elaborar suas próprias propostas de redação, inserida em uma visão de produto e reescrita que contribuem para que a interação realmente ocorra em sala de aula.

Essas duas construções da imagem do professor também não afastam os consumidores do Livro Didático do material, pois antecipam e respondem a discursos comuns na escola, como: é preciso conduzir o professor, pois sua formação e carga horária não the permitem preparar aulas com qualidade; o professor deve ser o agente principal do ensino, por isso, é preciso que o Livro Didático seja mais um instrumento de ensino e um material de apoio.

\section{Conclusões}

A proposta, neste artigo, foi contextualizar o livro didático inserido em uma conjuntura de leis e documentos destinados ao Ensino Médio. Para tanto, apresentou-se, brevemente, a trajetória do PNLD e entendeu-se que a elaboração do Guia do PNLD foi importante, pois um grupo de especialistas pode avaliar os livros e apresentar em "resenhas" as conclusões a que 
chegaram.

Entendeu-se que os PCN e os Livros Didáticos contribuíram fortemente para que uma concepção de linguagem, de língua e de escrita fosse divulgada, principalmente, no ambiente escolar, e que essas concepções ajudam a entender os papéis atribuídos a professores e a alunos no processo de ensino-aprendizado.

Diante dessa conjuntura, a ideia foi depreender as concepções de linguagem e de ensino em que se respaldam os livros didáticos. Apresentaram-se, então, algumas propostas para a produção escrita presentes na seção "Leitura e Produção" do volume 3 da obra "Coleção Novas Palavras" de Emília Amaral et al. (2016) e como metodologia escolheram-se três propostas: duas de vestibular e uma elaborada pelos autores da obra.

Inseridas nos estudos do discurso e da linguagem, as análises procuraram observar quais são as teorias de escrita contempladas no material e como resultado observou-se que há pelo menos duas: a primeira em que se privilegia a estrutura composicional de um gênero discursivo, o que pode favorecer os parâmetros restritos à gramática; e a segunda, em que a escrita é contextualizada e inserida em uma perspectiva de reescrita.

Entende-se que essas duas concepções não são vistas como contraditórias, pois antecipam críticas à produção descontextualizada com as questões do vestibular e com a norma culta. Ao mesmo tempo, a proposta com diferentes gêneros responde a teorias linguísticas mais contemporâneas, que abrem espaço para a interação entre os textos e aproxima o Livro Didático de questões postas, principalmente, nos PCN.

A partir da depreensão das concepções de linguagem e de escrita, pode-se, ainda, perceber a construção de imagens no que se refere ao professor como heterogênea. Há uma perspectiva de que ele deve seguir uma trajetória proposta no material, o que pode tirar a autonomia desse profissional, e outra que é dada pela oportunidade de trabalho com diferentes textos e linguagens multissemióticas. Essas duas construções também parecem não se excluírem, pois, conforme apresentamos, nelas ressoam imagens de professores que são aptos a escolherem o próprio material e de profissionais que pouco tempo têm para preparar as aulas.

Por fim, o Livro Didático, apesar de poder ser selecionado pelo professor, passa por um filtro com vários critérios que o incluem ou excluem do Guia do PNLD. Nesse sentido, o professor pode entender esse instrumento como uma imposição e, com isso, aderir, sem restrições, aos 
conceitos e às atividades nele propostas. No entanto, em nosso ver, o docente deve entender o Livro Didático como um material de apoio e buscar práticas, como escolher seus próprios textos, selecionar gêneros, pensar como será a reescrita, para se sentir fortalecido na interação com os alunos no ensino-aprendizado.

\section{Referências}

ALENCAR, A. G. O gênero debates nos livros didáticos de português do ensino médio: vozes em diálogo. 2017. 263f. Tese (Doutorado em Letras) - Universidade de São Paulo, São Paulo. 2017. Disponível em: http://www.teses.usp.br/teses/disponiveis/8/8142/tde-23052018-112103/ptbr.php.Acesso em 20 jul. 2019.

AMARAL, E. et al. Novas Palavras: 3ㅇan ano, ensino médio, manual do professor, componente curricular língua portuguesa [coleção novas palavras]. 3.ed., São Paulo: FTD, 2016.

BAGNO, M. Preconceito linguístico: o que é, como se faz. 11.ed. São Paulo: Loyola, 2002.

BAKHTIN, M. Estética da criação verbal. 4.ed. São Paulo: Martins Fontes, 2003.

BAKHTIN M.; VOLOCHÍNOV. Marxismo e filosofia da linguagem. 12.ed. São Paulo: Hucitec, 2006.

BATISTA, A. A. G. A avaliação dos livros didáticos: para entender o Programa Nacional do Livro Didático (PNLD). In: BATISTA, A. A. G. A.; ROJO, R. (orgs.). Livro didático de língua portuguesa: letramento e cultura da escrita, Campinas: Mercado de Letras, 2003, p.25-68.

BRAIT, B. Análise e teoria do discurso. In: BRAIT, B. (org.). Bakhtin: outros conceitos-chave. São Paulo: Contexto, 2008, p.9-32.

BRASIL. Senado Federal. Lei de diretrizes e bases da educação nacional: no 9394/96. Brasília: 1996.

BRASIL. MEC. Secretaria de Educação Média e Tecnológica. Parâmetros curriculares nacionais do ensino médio. Brasília, 2000.

BRASIL. Ministério da Educação. Secretaria de Educação Média e Tecnológica. PCNs+ensino médio: orientações educacionais complementares aos parâmetros curriculares nacionais. Brasília, 2002.

BRASIL. Ministério da Educação. Ciências humanas e suas tecnologias [orientações curriculares para o ensino médio, vol. 3]. SEB: Brasília, 2006.

BRASIL. Ministério da Educação. Secretaria de Educação Básica. Diretoria de Currículos e Periódico Horizontes - USF - Itatiba, SP - Brasil - e020031 
Educação Integral. Diretrizes Curriculares para o Ensino Médio. In: Diretrizes Nacionais Gerais da Educação Básica. Brasília: MEC/SEB/DICEI, 2013.

BRASIL. Ministério da Educação. PNLD 2018: apresentação - guia de livros didáticos - ensino médio. DF: MEC/SEB, 2017a.

BRASIL. Ministério da Educação. PNLD 2018: língua portuguesa - guia de livros didáticos ensino médio. DF: MEC/SEB, 2017b.

GERALDI, J. W. Portos de passagem. 4.ed. São Paulo: Martins Fontes, 1997.

GERALDI, J. W. Concepções de linguagem e ensino de português. In: GERALDI, J. W. (org.). $O$ texto na sala de aula. 4.ed. São Paulo: Ática, 2006, p.39-46.

LAJOLO, M. Livro didático: um (quase) manual de usuário. Em Aberto, Brasília, n.69, v.16, p.3-9, jan./mar. 1996.

POSSENTI, S. Por que (não)ensinar gramática na escola. Campinas: Mercado de Letras,1996.

SILVA, E. T. Livro didático: do ritual de passagem à ultrapassagem. Em Aberto, Brasília, n.69, v.16, p.11-15, jan./mar. 1996.

TRAVAGLIA, L. C. Gramática e interação: uma proposta para o ensino de gramática no 1ㅇ e 2응 graus. 6.ed. São Paulo: Editora Cortez, 2001.

WITTKE, C. I. Ensino de língua materna: PCNs, gramática e discursos. Santa Cruz do Sul: EDUNISC, 2007.

Recebido em outubro 2019.

Aprovado em maio 2020. 